\title{
Absolute Circulating Leukemic Cells as a Risk Factor for Early Bleeding Events in Patients with Non-High-Risk Acute Promyelocytic Leukemia
}

\section{Yanru Pei $\mathbb{D}^{*}$ \\ Mingyue Shi (D)* \\ Juanjuan Song $\mathbb{D}$ \\ Xiaona Niu (1D \\ Shengjie Wei (iD \\ Liurui Dou \\ Mengyu Xiao \\ Dan Li \\ Fangfang Xu (D) \\ Yanliang Bai \\ Kai Sun (D)}

Department of Hematology, Zhengzhou University People's Hospital and Henan Provincial People's Hospital, Henan, People's Republic of China

*These authors contributed equally to this work
Correspondence: Kai Sun; Yanliang Bai Department of Hematology, Zhengzhou University People's Hospital and Henan Provincial People's Hospital, No. 7 Weiwu Road, Jinshui District, Zhengzhou, Henan, 450003, People's Republic of China

Tel +86-I8237II0038; +86- I37836052II

Emailsunkai@cellscience.org;

yanliangbai@I26.com
Background: Hemorrhagic complications are the most common cause of early death in patients with APL and remain a major challenge in the management of APL. Early fatal bleeding events occur not only in high-risk but also in non-high-risk acute promyelocytic leukemia (APL) patients with normal or low WBC counts.

Objectives and Methods: To demonstrate the role of the absolute number of circulating leukemic cells in early bleeding events in APL patients. Clinical and laboratory characteristics of 149 patients newly diagnosed with APL were obtained from medical records and retrospectively investigated.

Results: In this study, circulating absolute leukemic cells were positively correlated with the WBC count $(r=0.9813, p<0.001)$ in all patients with APL, and importantly, they were strongly associated with significant bleeding events in non-high-risk patients. Multivariate logistic regression analysis showed that the absolute number of leukemia cells was an independent risk factor for significant bleeding events in APL patients. A cut-off value of $2.59 \times 10^{9} / \mathrm{L}$ for circulating leukemic cells to predict significant bleeding events in APL patients was obtained by ROC curve analysis. We further confirmed that the significant bleeding rate of patients with non-high-risk APL was statistically increased when the absolute number of circulating leukemic cells was $\geq 2.59 \times 10^{9} / \mathrm{L}$.

Conclusion: Circulating leukemic cell content has great clinical value for predicting early bleeding events in APL patients, especially in non-high-risk APL.

Keywords: circulating leukemic cells, early fatal bleeding events, non-high-risk acute promyelocytic leukemia

\section{Introduction}

Acute promyelocytic leukemia (APL), a unique subtype of acute myeloid leukemia (AML), is characterized by unique morphology of blast cells. The vast majority of APL patients have a specific chromosomal translocation, $t(15 ; 17)$, forming a fusion transcript between the promyelocytic leukemia (PML) gene and the retinoic acid receptor $(\mathrm{RAR} \alpha)$ gene, called PML-RAR $\alpha{ }^{1,2}$ All-trans retinoic acid (ATRA), which can promote terminal differentiation of malignant promyelocytes into mature granulocytes, has revolutionized the treatment of APL. The combination of ATRA and arsenic trioxide (ATO) or cytotoxic chemotherapy has induced response rates in excess of $90 \%$ and long-term leukemia-free survival rates in excess of $80 \%$. APL has evolved from being a deadly to a highly curable disease. $^{3-13}$ 
Despite advances in the treatment of APL, early death rates have remained relatively constant. Hemorrhagic complications are the most common cause of early death in patients with APL and remain a major challenge in the management of APL. ${ }^{11,14-22}$ It is worth noting that the major risk assessment method based on WBC count was initially used to assess the risk of relapse rather than the risk of early death resulting from fatal hemorrhage. ${ }^{23-25}$ Thus, it is critical to identify risk factors for early fatal bleeding events in APL patients. Several laboratory markers and parameters related to major hemorrhage or hemorrhagic death have been investigated. Among all the parameters involved in early fatal bleeding events, WBC count is frequently related to APL disease burden and served as a convenient predictor of fatal hemorrhage in APL at diagnosis in some studies. ${ }^{13,18,19,26-35}$ However, other studies have proved that there is no significant association between WBC count and bleeding risk. ${ }^{36,37}$ Thus, the value of WBC count as a risk factor for early bleeding events is limited, especially in non-high-risk APL patients with normal or low WBC counts.

The circulating leukemic cell count in APL can reflect the disease burden. The coagulopathy of APL is principally impelled by proteins on the surface of APL cells, such as tissue factor (TF) and Annexin II. ${ }^{38-42}$ Therefore, we performed a study to examine the clinical significance of the absolute number of circulating leukemic cells and determine the cut-off value for detecting early significant bleeding in APL patients, especially in non-high-risk APL patients. These experiments were performed with an aim to identify patients at the greatest risk of hemorrhage to ultimately actively prevent hemorrhage.

\section{Materials and Methods}

\section{Patients}

This retrospective study included 149 patients diagnosed with APL treated at Zhengzhou University People's
Hospital and its alliance hospital from December 2016 to September 2020. All patients were newly diagnosed with typical APL, who confirmed t $(15 ; 17)$ and/or PML-RAR $\alpha$ fusion genes. M3v type of APL was excluded from our study. This study was conducted in accordance with the Declaration of Helsinki, and was approved by the research ethics committees of each institution. Each participant signed a written informed consent form before enrollment, and a parent or legal guardian of patients under 18 years of age provided informed consent.

\section{Laboratory Characteristics}

All clinical characteristics were obtained from medical records, including age, sex, WBC count, circulating leukemic cell percentage and absolute number, bone marrow leukemic promyelocyte (BMP) percentage, platelet (PLT) count, hemoglobin (HB), prothrombin time (PT) (normal range: 11-17 s), activated partial thromboplastin time (APTT) (normal range: $23-43.5 \mathrm{~s}$ ), fibrinogen (FIB) (normal range: 2-4 g/L), D-dimer (normal range: $0-0.5 \mathrm{mg} / \mathrm{L}$ ), lactate dehydrogenase (LDH) (normal range: 120-250 U/L), and creatinine (CREA) (normal range: $58-110 \mu \mathrm{mol} / \mathrm{L})$. Circulating leukemic cells, also termed peripheral blood promyelocytes, are atypical hypergranular cells and classified as blasts in APL. In typical APL blood smears, the morphologic features of such cells are characterized by a uniform morphology, unevenly sized granules in the cytoplasm, and Auer rods can be seen in some cells (Figure 1). The number of absolute circulating leukemic cells was obtained by multiplying the WBC count from the routine blood test by the percentage of circulating leukemic cells in the blood smear, and the two detection samples were obtained at the same time.

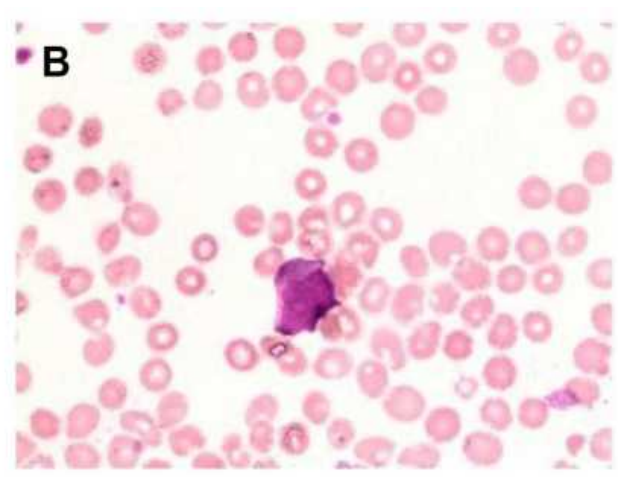

Figure I Circulating leukemic cells from peripheral blood smears of different patients (A and B). 


\section{Definitions}

To evaluate the severity of bleeding manifestations of APL, the widely used World Health Organization (WHO) severity grading system and the modified WHO scale by Kaufman were used in this study. ${ }^{43-45}$ A summary of the revised WHO bleeding scale is provided in Supplementary Table 1. According to the bleeding grade, the APL patients were divided into two groups: the nonsignificant bleeding group (grades 0,1 , and 2) and the significant bleeding group (grades 3 and grade 4). Early death (ED) was defined as death from any cause within 30 days after diagnosis. Hemorrhagerelated ED (HED) was defined as death due to bleeding events within 30 days. According to the WBC count (< or $\geq 10 \times 10^{9} / \mathrm{L}$ ) at APL diagnosis, the patients were stratified into a non-high-risk group and a high-risk group. $^{23}$

\section{Treatment Strategies}

After diagnosis of APL, ATRA ( $25 \mathrm{mg} / \mathrm{m} 2 /$ day) combined with ATO $(0.16 \mathrm{mg} / \mathrm{kg} /$ day $)$ was administered until the patients achieved complete remission (CR). On the second day of treatment in patients with highrisk APL or when WBC counts were $\geq 10 \times 10^{9} / \mathrm{L}$ in the non-high-risk group during induction therapy, additional chemotherapy (idarubicin $8 \mathrm{mg} / \mathrm{m}^{2} /$ day for $3-4$ days or daunorubicin $45 \mathrm{mg} / \mathrm{m}^{2} /$ day for 3-4 days) was administered to control hyperleukocytosis. If patients were diagnosed with differentiation syndrome (DS) during therapy, ATRA was temporarily suspended, and dexamethasone was given until the clinical symptoms resolved. PLT transfusion was performed to maintain a PLT count in the range of $30-50 \times 10^{9} / \mathrm{L}$. Fresh-frozen plasma and cryoprecipitate were infused to maintain fibrinogen levels at $1.5 \mathrm{~g} / \mathrm{L}$ and the PT and APTT near the normal range.

\section{Statistical Analysis}

The chi-square test or Fisher's exact test was used to compare categorical variables. For continuous variables, the Mann-Whitney $U$-test was used to compare the characteristics of the baseline data for each group. A logistic regression model was used for multifactorial analysis. Using the receiver operating characteristic curve (ROC) method, the optimal cutoff values of circulating leukemic cells to predict significant bleeding events in APL patients was determined. All statistical analyses were performed using SPSS version 24.0, and graphs were drawn with GraphPad Prism version 8.0 , and $\mathrm{p}<0.05$ was considered to indicate statistical significance.

\section{Results}

\section{Clinical and Laboratory Characteristics of the Patients}

This study retrospectively analyzed the clinical and laboratory characteristics of 149 newly diagnosed APL patients ( 76 males and 73 females). The median age was 40 years (range 3-83 years). The baseline characteristics are shown in Table 1. Patients were stratified into a non-high-risk group (WBC count $<10 \times 10^{9} / \mathrm{L}, 94$ patients, $63.1 \%$ ) and a high-risk group (WBC count $\geq 10 \times 10^{9} / \mathrm{L}, 55$ patients, $36.9 \%$ ) according to the WBC count at the time of initial diagnosis. Based on the bleeding grade, the APL patients were divided into two groups: the nonsignificant bleeding group (grades 0,1 and 2, 102 patients, 68.5\%) and the significant bleeding group (grades 3 and 4, 47 patients, 31.5\%). Among the 149 patients with APL, 2 patients died before treatment, 58 patients received ARTA + ATO treatment, and 89 patients received ATRA + ATO + IDA/DNR treatment. ED occurred in 12 patients $(8.1 \%)$, of which $9(75 \%)$ died from bleeding events, making them the leading cause of ED. The main causes of HED were intracranial hemorrhage (8 patients) and alveolar hemorrhage (1 patient).

\section{Patient with Significant Bleeding Events}

Of the 149 patients, 47 patients (31.5\%) had significant bleeding (grades 3 and 4), which mainly occurred in the oropharyngeal, nasal, mucosa, skin, lung, and brain regions. A total of 33 patients $(22.1 \%)$ had grade 3 bleeding, including bleeding requiring red blood cell transfusion in addition to routine transfusion needs and bleeding associated with moderate hemodynamic instability. Fourteen patients (9.4\%) had grade 4 bleeding, including bleeding associated with severe hemodynamic instability, fatal bleeding and central nervous system (CNS) bleeding on imaging with or without dysfunction. The median time to grade 4 bleeding events was 6 days (0-25 days). Among the 14 patients with grade 4 bleeding, 10 patients had intracranial hemorrhage, and 2 patients had alveolar hemorrhage. All grade 4 bleeding patients also had skin and mucous membrane bleeding, gum bleeding, and epistaxis. The basic clinical characteristics of the patients with grade 4 bleeding are shown in Table 2. 
Table I Patient Demographics and Baseline Characteristics

\begin{tabular}{|c|c|c|}
\hline Clinical Characteristics & $\begin{array}{l}\text { Normal } \\
\text { Range }\end{array}$ & $\begin{array}{l}\text { Median (Range)/N } \\
\text { (\%) }\end{array}$ \\
\hline Age & & $40(3-83)$ \\
\hline Sex (n) & & \\
\hline Male & & $76(51 \%)$ \\
\hline Female & & $73(49 \%)$ \\
\hline WBC $\left(\times 10^{9} / \mathrm{L}\right)$ & $3.5-9.5$ & $4.13(0.37-258.01)$ \\
\hline $\begin{array}{l}\text { Circulating leukemic cell } \\
\text { percentage (\%) }\end{array}$ & & $57(0-98.5)$ \\
\hline $\begin{array}{l}\text { Absolute number of circulating } \\
\text { leukemic cells }\left(\times 10^{9} / \mathrm{L}\right)\end{array}$ & & $2.08(0-250.27)$ \\
\hline BMP (\%) & & $83(13-95.4)$ \\
\hline PLT $\left(\times 10^{9} / L\right)$ & $125-350$ & $25(1-319)$ \\
\hline HGB (g/L) & $130-175$ & $82(35-136)$ \\
\hline PT (s) & $11-17$ & $14.5(9.8-27.4)$ \\
\hline APTT (s) & $28-43.5$ & $28.9(15.3-54.1)$ \\
\hline FIB (g/L) & $2-4$ & $1.20(0.19-6.01)$ \\
\hline D-Dimer (mg/L) & $0-0.05$ & $16.04(0.7 I-152.53)$ \\
\hline LDH (U/L) & $120-250$ & $306(113-7836)$ \\
\hline CREA ( $\mu \mathrm{mol} / \mathrm{L})$ & $58-110$ & $57(22-18 \mid)$ \\
\hline Risk groups (n) & & \\
\hline Standard-risk group & & $94(63.1 \%)$ \\
\hline High-risk group & & $55(36.9 \%)$ \\
\hline Bleeding (n) & & \\
\hline Significant bleeding & & 47 (31.5\%) \\
\hline Nonsignificant bleeding & & $102(68.5 \%)$ \\
\hline Thrombosis & & \\
\hline Yes & & $13(8.7 \%)$ \\
\hline No & & $136(91.3 \%)$ \\
\hline DS & & \\
\hline Yes & & $50(33.6 \%)$ \\
\hline No & & $99(66.4 \%)$ \\
\hline ED & & \\
\hline Yes & & $12(8.1 \%)$ \\
\hline No & & $137(91.9 \%)$ \\
\hline
\end{tabular}

Abbreviations: WBC, white blood cell; BMP, bone marrow leukemic promyelocyte; PLT, platelets; HB, hemoglobin; PT, prothrombin time; APTT, activated partial thromboplastin time; FIB, fibrinogen; LDH, lactate dehydrogenase; CREA, creatinine; $D S$, differentiation syndrome; $E D$, early death.

\section{Risk Factors for Hemorrhage}

The clinical characteristics of patients in the significant bleeding group (47 patients) were compared to those of patients in the nonsignificant bleeding group (102 patients). The results showed that WBC count ( $p=0.013$, Figure 2A), circulating leukemic cell

\begin{tabular}{|c|c|}
\hline 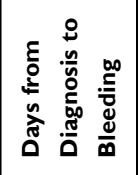 & $\simeq$ rom $n m a \circ 0$ m \\
\hline 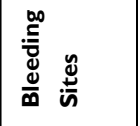 & 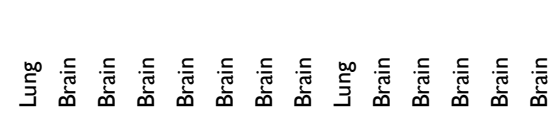 \\
\hline 芯 & 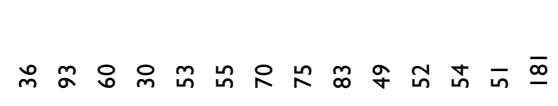 \\
\hline I & 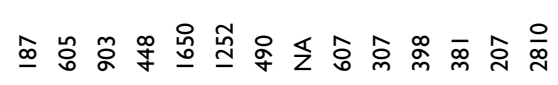 \\
\hline 离 & 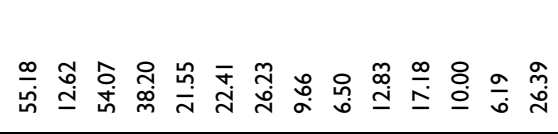 \\
\hline$\frac{m}{4}$ 하 ح & 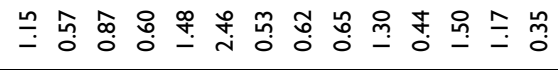 \\
\hline$\stackrel{5}{\frac{5}{\alpha}}$ & 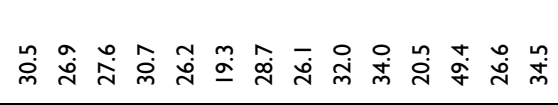 \\
\hline $5 \widehat{a}$ & 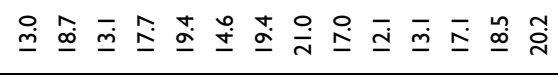 \\
\hline$\stackrel{m}{I}$ 히 & 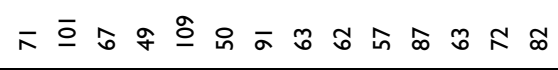 \\
\hline$\frac{\overline{0}}{\bar{\alpha}} د$ & 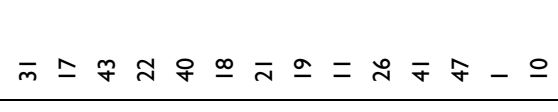 \\
\hline$\sum_{m}^{a} \precsim$ & 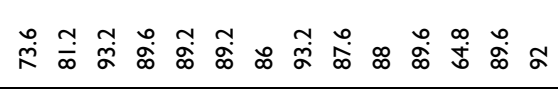 \\
\hline 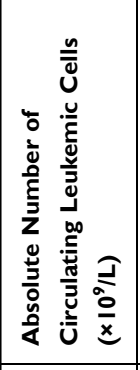 & 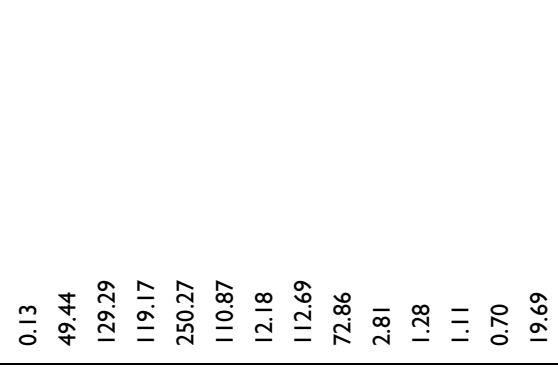 \\
\hline 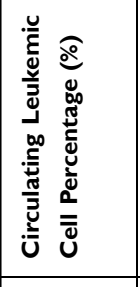 & 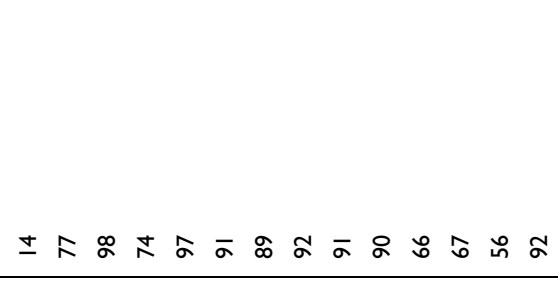 \\
\hline 誉高 & 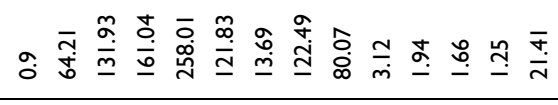 \\
\hline 离 & 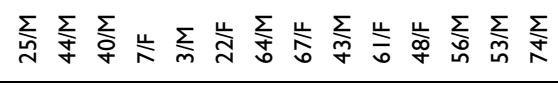 \\
\hline 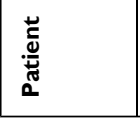 & $-4 m+n \circ h \infty a \leq= \pm \underline{m}$ \\
\hline
\end{tabular}


A

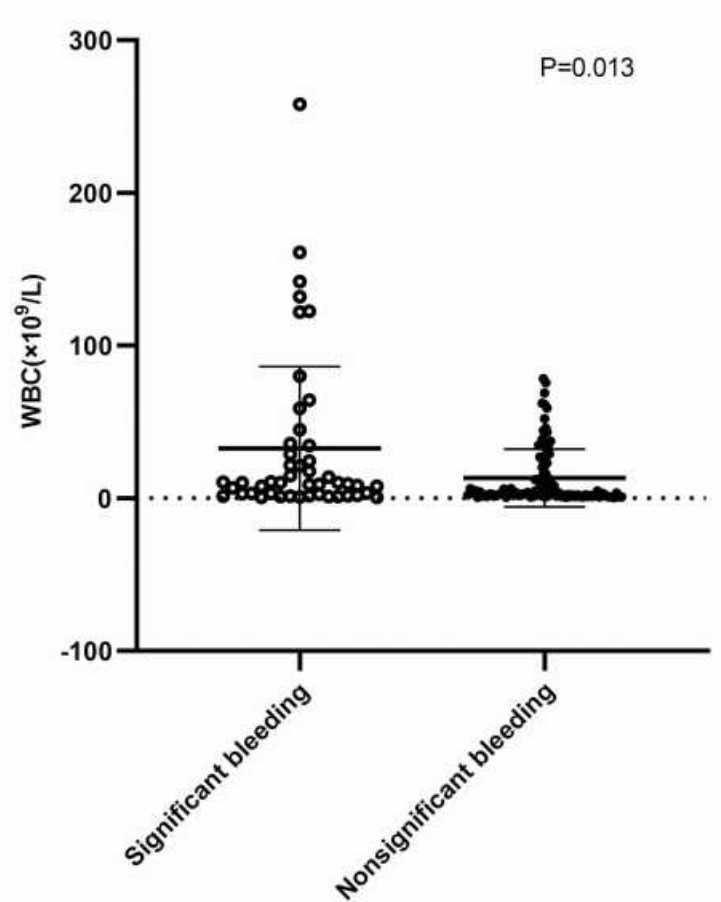

B

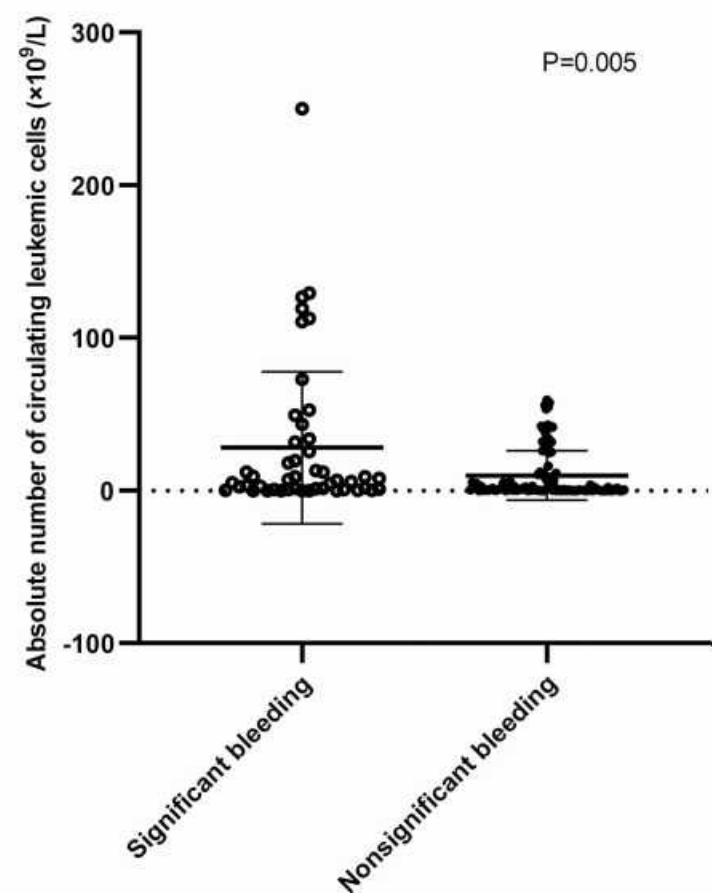

Figure 2 Laboratory data showed that there were significant differences in WBC count $(\mathbf{A})$ and absolute number of circulating leukemic cells (B) between patients with or without significant bleeding.

percentage $(p=0.002)$, absolute number of circulating leukemic cells $(p=0.005$, Figure 2B), BMP $(p=0.003)$, PT $(p<0.001)$, FIB $(p=0.009)$, D-dimer $(p<0.001)$ and LDH $(p=0.03)$ were obviously associated with significant bleeding (Table 3 ).

\section{Correlation Between the Absolute Number of Circulating Leukemic Cells and the WBC Count}

As both the WBC count and the absolute number of circulating leukemic cells were associated with bleeding events, we next analyzed the correlation of the WBC count with the circulating leukemic cell percentage and the absolute number of circulating leukemic cells in APL patients. We found that the circulating leukemic cell percentage was not correlated with the WBC count (Figure 3A). In contrast, the absolute number of circulating leukemic cells was positively correlated with the WBC count $(\mathrm{r}=0.9813, p<0.001$; Figure 3B). Additionally, we further analyzed the correlation of the WBC count with the circulating leukemic cell percentage and the absolute number of circulating leukemic cells in the non-high-risk and high-risk groups. Similarly, the circulating leukemic cell percentage was not evidently correlated with the WBC count in either high-risk or non-high-risk group patients (Figure 3C and E). As expected, the absolute number of circulating leukemic cells was positively correlated with the WBC count in the high-risk group ( $\mathrm{r}=0.9727, p<0.001$, Figure 3D). In the non-high-risk group, there was also a positive linear correlation between the absolute number of circulating leukemic cells and the WBC count $(\mathrm{r}=0.8788, p<0.001$, Figure 3F).

\section{Multivariate Logistic Regression Analysis of Risk Factors for Significant Bleeding Events in APL Patients}

The bleeding events in APL patients was considered as the dependent variable, and the absolute number of leukemia cells, BMP, PT, FIB, D-dimer and LDH were included in logistic regression model (WBC count, the circulating leukemic cell percentage and the absolute number of circulating leukemic cells were correlated in APL, so only the absolute number of circulating leukemic cells was included in logistic regression model). The result showed that the absolute number of leukemia cells $(\mathrm{OR}=1.017$, 95\% CI: $1.000-1.013, p=0.045)$ was an independent risk factor for significant bleeding events in APL patients (Table 4). 
Table 3 Main Characteristics of Patients with or without Significant Bleeding

\begin{tabular}{|c|c|c|c|}
\hline Clinical Characteristics & Significant Bleeding $(n=47)$ & Nonsignificant Bleeding $(n=102)$ & $p$-value \\
\hline Age & $44(3-74)$ & $40(8-83)$ & 0.426 \\
\hline $\operatorname{Sex}(n)$ & & & 0.487 \\
\hline Male & 22 & 54 & \\
\hline Female & 25 & 48 & \\
\hline WBC $\left(\times 10^{9} / L\right)$ & $10.00(0.49-258.01)$ & $3.11(0.37-78.19)$ & 0.013 \\
\hline Circulating leukemic cell percentage (\%) & $77(0-98.5)$ & $41(0-97.5)$ & 0.002 \\
\hline Absolute number of circulating leukemic cells $\left(\times 10^{9} / \mathrm{L}\right)$ & $6.78(0-250.27)$ & $1.20(0-59.21)$ & 0.005 \\
\hline BMP (\%) & $86.8(13-95.4)$ & $81.1(29.5-94.4)$ & 0.003 \\
\hline PLT $\left(\times 10^{9} / L\right)$ & $22(I-84)$ & $27(4-319)$ & 0.117 \\
\hline PT (s) & $17(11-27.4)$ & $13.55(9.8-25.4)$ & $<0.001$ \\
\hline APTT (s) & $28.5(19.3-49.4)$ & $28.9(15.3-54.1)$ & 0.967 \\
\hline FIB $(g / L)$ & $1.02(0.31-3.33)$ & $1.35(0.19-6.01)$ & 0.009 \\
\hline D-Dimer (mg/L) & $20.00(4.17-81.2)$ & $10.93(0.71-152.53)$ & $<0.001$ \\
\hline LDH (U/L) & $381(136-2810)$ & $278(113-7836)$ & 0.03 \\
\hline CREA ( $\mu \mathrm{mol} / \mathrm{L})$ & $54(25-|8|)$ & $58(22-154)$ & 0.202 \\
\hline
\end{tabular}

\section{Limitations of the WBC Count for Predicting Hemorrhage}

In the ATRA era, the prognostic stratification of patients with APL is based on the WBC count at initial diagnosis, with $\mathrm{WBC}$ count $\geq 10 \times 10^{9} / \mathrm{L}$ categorizing patients into the high-risk group. Studies have identified that a WBC count over $10 \times 10^{9} / \mathrm{L}$ is more associated with bleeding than a $\mathrm{WBC} \leq 10 \times 10^{9} / \mathrm{L}$. Consistent with this idea, our results demonstrated that the incidence of significant bleeding was obviously higher in patients with $\mathrm{WBC} \geq 10 \times 10^{9} / \mathrm{L}$ ( $p=0.015$, Figure 4 ). The data indicated that patients in the high-risk group had a higher risk of significant bleeding than patients in the non-high-risk group. However, in the non-high-risk group (WBC $<10 \times 10^{9} / \mathrm{L}$ ), there were still some patients with significant bleeding. Thus, the WBC count has limitations in predicting early bleeding events in the non-high-risk group, which had normal or low WBC counts.

\section{The Role of the Absolute Number of Circulating Leukemic Cells in Predicting Bleeding Events}

Since the absolute number of circulating leukemic cells was identified as a risk factor for bleeding events in APL, we next investigated the potential roles of the absolute number of circulating leukemic cells in predicting hemorrhage events in APL patients. The cut-off value for the absolute number of circulating leukemic cells to predict significant bleeding events was obtained by ROC curve analysis $\left(2.59 \times 10^{9} / \mathrm{L}\right)$. Then, patients were divided into two groups: the absolute number of circulating leukemic cells $\geq 2.59 \times 10^{9} / \mathrm{L}$ group and the absolute number of circulating leukemic cells $<2.59 \times 10^{9} / \mathrm{L}$ group. The rate of significant bleeding was remarkably different between the two groups ( $p=0.002$, Figure 5A), implying that patients with an absolute number of circulating leukemic cells $\geq 2.59 \times 10^{9} / \mathrm{L}$ are more likely to have significant bleeding than those with an absolute number of circulating leukemic cells $<2.59 \times 10^{9} / \mathrm{L}$. In addition, WBC count ( $p \quad<0.001$ ), circulating leukemic cell percentage $(p=0.002)$, BMP percentage $(p<0.001)$, PT $(p<0.001)$, APTT $(p=0.004)$, FIB $(p<0.001)$, D-dimer $(p=0.016)$, LDH $(p<0.001)$, and CREA $(p=0.016)$ were significantly different between the two groups (Table 5). More importantly, when patients in the non-high-risk group were divided by the absolute number of circulating leukemic cells, the incidence of significant bleeding was much higher in patients with an absolute number of circulating leukemic cells $\geq 2.59 \times 10^{9} / \mathrm{L}$ than in those with an absolute number of circulating leukemic cells $<2.59 \times 10^{9} / \mathrm{L}$ ( $p=0.021$, Figure 5B). These results strongly demonstrated 

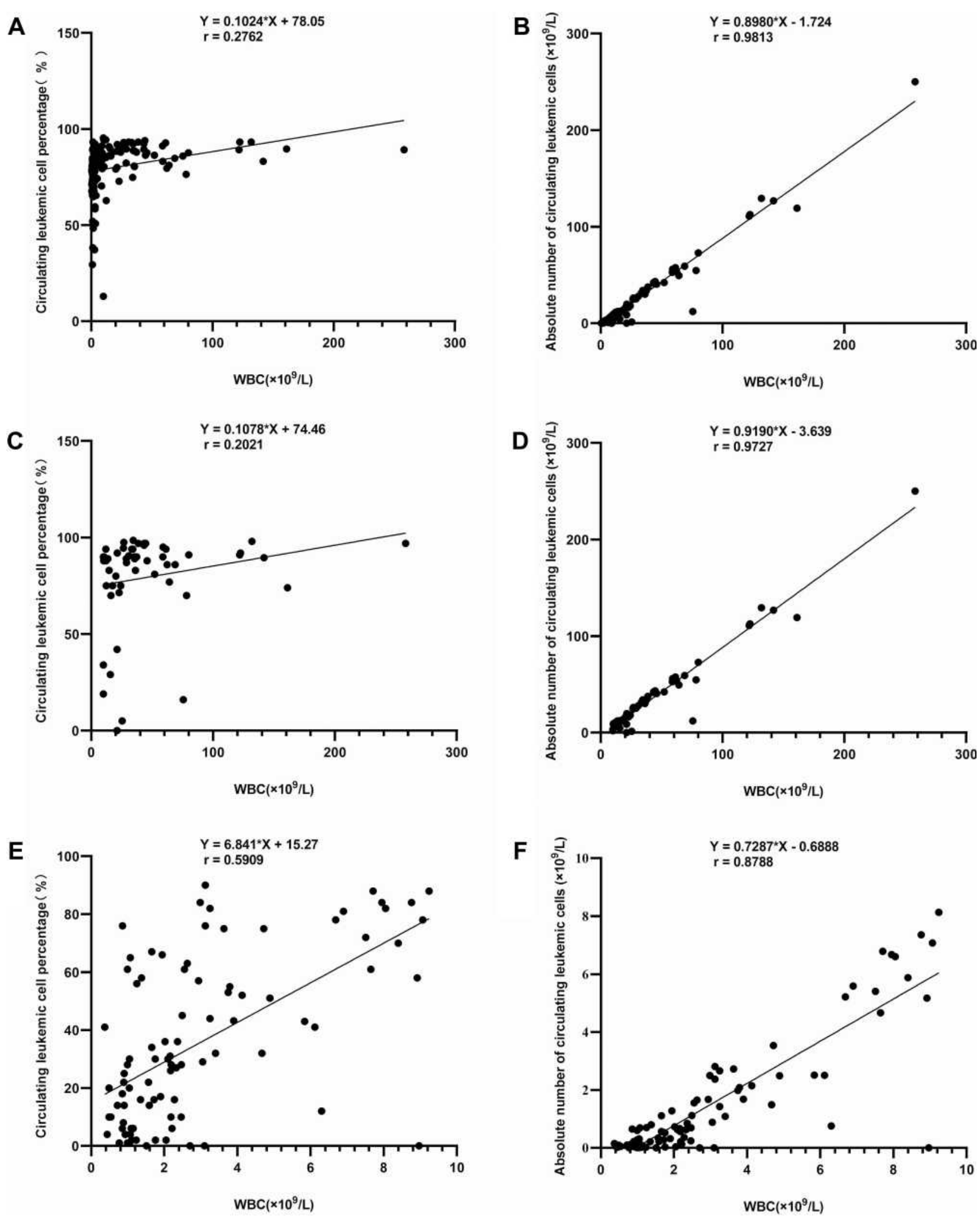

Figure 3 Correlation of WBC count with circulating leukemic cell percentage and absolute number of circulating leukemic cells. There was no evident correlation between circulating leukemic cell percentage and WBC count in all APL patients (A), the high-risk group $(\mathbf{C})$ or the non-high-risk group (E). The absolute number of circulating leukemic cells was positively correlated with the WBC count in all APL patients (B), the high-risk group (D) and the non-high-risk group (F). 
Table 4 Multivariate Analysis of Risk Factors for Significant Bleeding Events

\begin{tabular}{|c|c|c|c|}
\hline Clinical Characteristics & p-value & OR & $95 \% \mathrm{Cl}$ \\
\hline Absolute number of circulating leukemic cells $\left(\times 10^{9} / \mathrm{L}\right)$ & 0.045 & 1.017 & $1.000 \sim 1.013$ \\
\hline BMP (\%) & 0.501 & 1.012 & $0.978 \sim 1.047$ \\
\hline PT (s) & 0.149 & 1.115 & $0.962 \sim 1.292$ \\
\hline $\mathrm{FIB}(\mathrm{g} / \mathrm{L})$ & 0.168 & 0.708 & $0.433 \sim 1.159$ \\
\hline D-Dimer (mg/L) & 0.195 & 1.014 & $0.993 \sim 1.035$ \\
\hline LDH (U/L) & 0.160 & 0.999 & $0.999 \sim 1.000$ \\
\hline
\end{tabular}

that the absolute number of circulating leukemic cells is extremely critical for predicting early bleeding events in APL, especially in non-high-risk APL with normal or low WBC counts.

\section{Discussion}

Fatal bleeding events and HED, as the most common causes of induction failure, remain of vital concern in the treatment of APL patients. In this study, the significant bleeding rate was $31.5 \%$, and the incidence of early hemorrhagic death was $6 \%$, which is similar to that seen in previous studies. ${ }^{11,14-19,37}$ Moreover, the results presented here also demonstrate that the WBC count and routine clotting test parameters (such as PT and FIB) are associated with significant bleeding in APL, which was consistent with previous studies.
Patients with APL exhibited some abnormal coagulation test results, including low FIB levels and elevated PT, APTT and D-dimer. Although these abnormalities were not present at the same time or in all patients, they still endowed a high risk of fatal bleeding. ${ }^{6,46}$ Malignant promyelocytes mediate fibrinogenesis, enhance fibrinolysis and induce abnormal bleeding in patients with APL. Routine clotting parameters, such as PT, APTT, fibrinogen and D-dimer, are indirect measures and may not timely reflect the process of fibrinolysis. ${ }^{11,15}$ Therefore, coagulation markers appear to be poor predictors of early bleeding events in patients with APL.

Unlike laboratory markers of disseminated intravascular coagulation (DIC), the WBC count is frequently related to APL disease burden and has served as a convenient predictor of fatal hemorrhage in APL at

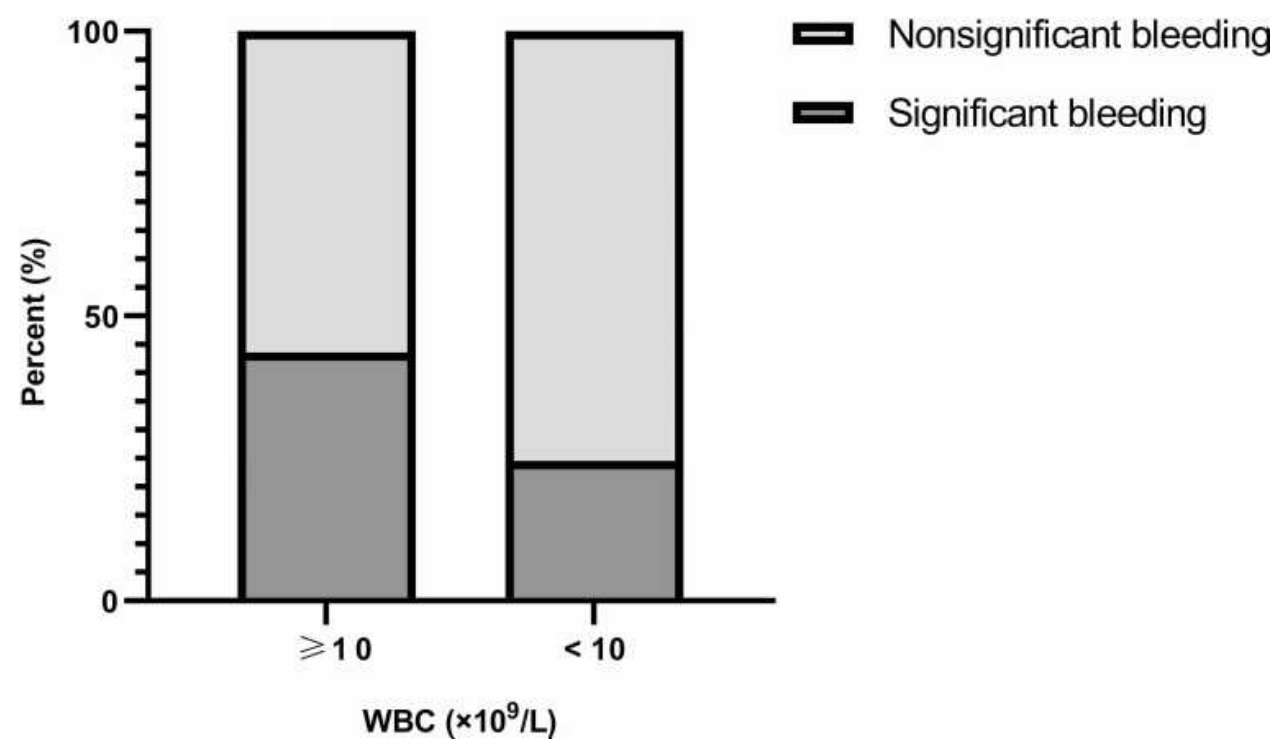

Figure 4 Association between WBC count and bleeding events. The significant bleeding rate was higher in patients with $\mathrm{WBC} \geq 10 \times 10^{9} / \mathrm{L}$ than in those with WBC $<10 \times 10^{9} /$ L. 
A

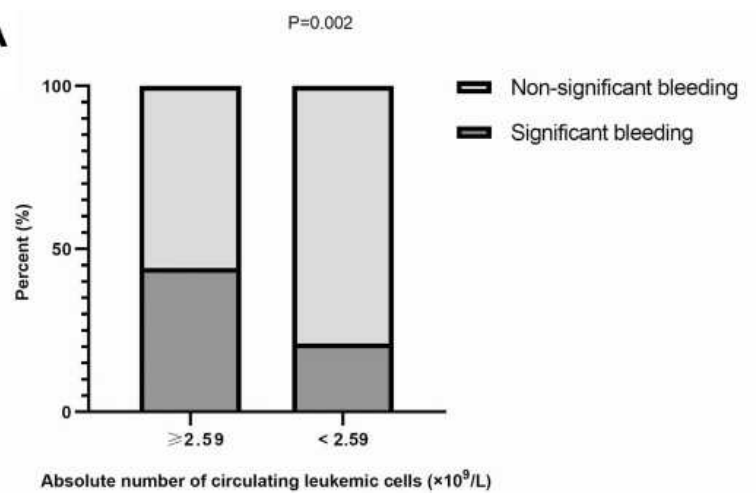

B

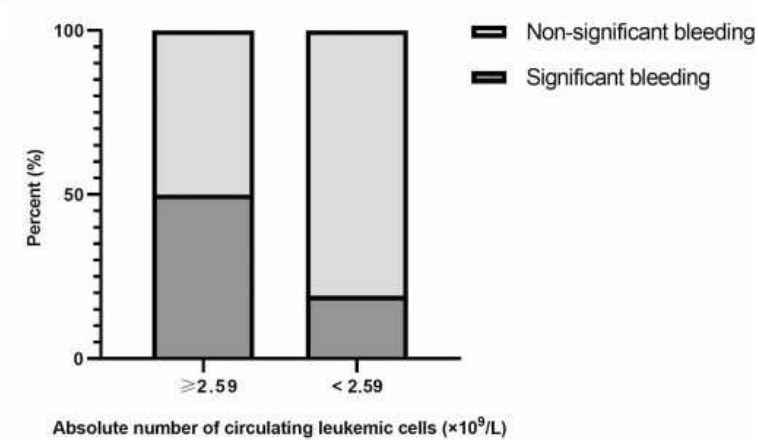

Figure 5 Association between absolute number of circulating leukemic cells and bleeding events. The significant bleeding rate was higher in patients with an absolute number of circulating leukemic cells $\geq 2.59 \times 10^{9} / \mathrm{L}$ than in those with an absolute number of circulating leukemic cells $<2.59 \times 10^{9} / \mathrm{L}$ in all patients with APL (A). In the non-high -risk group, the significant bleeding rate was higher in patients with peripheral blood promyelocyte counts $\geq 2.59 \times 10^{9} / \mathrm{L}(\mathbf{B})$.

diagnosis in some studies. As reported, factors associated with high bleeding risk include presenting WBC counts ranging from $10 \times 109 / \mathrm{L}$ to $30 \times 109 /$ L. $^{13,18,19,26-28,32-35}$ However, some studies have proved that there is no significant association between WBC count and bleeding risk. ${ }^{23,36,37}$ Thus, the value of the WBC count as a risk factor for early bleeding events is limited, especially in non-high-risk APL.
In this study, we focused on investigating the clinical value of the absolute number of circulating leukemic cells for predicting early significant bleeding in APL patients, especially in patients with non-high-risk APL. Our study emphasized that the absolute number of circulating leukemic cells, and not the leukemic cell percentage, in the peripheral blood was positively correlated with the WBC count in both high-risk and 46 non-high-risk group patients. Importantly, the results presented

Table 5 Main Characteristics of Our Series and Comparison of Groups with an Absolute Number of Circulating Leukemic Cells $\geq 2.59 \times 10^{9} / \mathrm{L}$ and $<2.59 \times 10^{9} / \mathrm{L}$

\begin{tabular}{|c|c|c|c|}
\hline Clinical Characteristics & $\begin{array}{l}\text { Absolute Number of Circulating } \\
\text { Leukemic Cells } \geq 2.59 \times 10^{9} / L \quad(n=68)\end{array}$ & $\begin{array}{c}\text { Absolute Number of Circulating } \\
\text { Leukemic Cells }<2.59 \times 10^{9} / L(n=81)\end{array}$ & p-value \\
\hline Age & $42(3-83)$ & $40(10-8 I)$ & 0.93 \\
\hline $\operatorname{Sex}(n)$ & & & 0.446 \\
\hline Male & 37 & 39 & \\
\hline Female & 31 & 42 & \\
\hline WBC $\left(\times 10^{9} / \mathrm{L}\right)$ & $26.57(3.12-258.01)$ & $1.76(0.37-25.40)$ & $<0.001$ \\
\hline $\begin{array}{l}\text { Circulating leukemic } \\
\text { cell percentage (\%) }\end{array}$ & $88(16-98.5)$ & $20(0-84)$ & $<0.001$ \\
\hline BMP (\%) & $86.6(13-95.4)$ & $78.4(29.5-93.2)$ & $<0.001$ \\
\hline PLT $\left(\times 10^{9} / L\right)$ & $22.5(6-84)$ & $29(1-319)$ & 0.254 \\
\hline PT(s) & $16.35(9.8-27.4)$ & I3.I (10.1-24.4) & $<0.001$ \\
\hline APTT(s) & $27(15.3-44.5)$ & $30.1(20.5-54.1)$ & 0.004 \\
\hline $\operatorname{FIB}(g / L)$ & $0.97(0.19-4.99)$ & $1.45(0.25-6.01)$ & $<0.001$ \\
\hline D-Dimer (mg/L) & $20.00(3.49-54.07)$ & II.04 (0.7I-I52.53) & 0.016 \\
\hline LDH (U/L) & $506.5(166-7836)$ & $238(|| 3-2 \mid 27)$ & $<0.001$ \\
\hline CREA ( $\mu \mathrm{mol} / \mathrm{L})$ & $6 I(28-|8|)$ & $53.5(22-154)$ & 0.016 \\
\hline
\end{tabular}


here definitively demonstrate that the absolute number of circulating leukemic cells is strongly associated with significant bleeding events in APL, not only in the high-risk group but also in the non-high-risk group. And the absolute number of leukemia cells was an independent risk factor for significant bleeding events in APL patients.

Another novel contribution of the current study is that a cut-off value for the absolute number of circulating leukemic cells as a risk factor for early bleeding events in patients with APL was obtained by ROC curve analysis. We further confirmed that the significant bleeding rate of patients with nonhigh-risk APL was statistically increased when the absolute number of circulating leukemic cells was $\geq 2.59 \times 10^{9} / \mathrm{L}$. Due to the limited number of patients and the relatively short followup duration, the results of the current study may be influenced by unrecognized bias. Thus, to further validate the present findings, larger-scale studies need to be performed in the future.

\section{Conclusion}

In conclusion, the absolute number of circulating leukemic cells is of great clinical value for identifying patients at the greatest risk of hemorrhage and actively preventing early bleeding events in APL, especially in patients with non-highrisk APL.

\section{Ethics Approval and Consent to Participate}

The study protocol was approved by the research ethics committees of Zhengzhou university people's hospital and hospital league. Each participant signed a written informed consent form before enrolment, and a parent or legal guardian of patients under 18 years of age provided informed consent.

\section{Acknowledgments}

We would like to express our gratitude to all the doctors, nurses and pathologists of all the hospitals and hematology departments who participated in this survey. Our manuscript has been edited in English to correct grammar or process.

\section{Author Contributions}

All authors made a significant contribution to the work reported, whether that is in the conception, study design, execution, acquisition of data, analysis and interpretation, or in all these areas; took part in drafting, revising or critically reviewing the article; gave final approval of the version to be published; have agreed on the journal to which the article has been submitted; and agree to be accountable for all aspects of the work.

\section{Funding}

This study was partially supported the National Natural Science Foundation of China (No. 81971508, No. 81471589), the foundation and frontier research grant of Henan provincial science and technology bureau, PR China (No.112300410027), and Henan Province Medical Science and Technology Tackling Program joint co-construction project, PR China (No.LHGJ20190579).

\section{Disclosure}

The authors report no conflicts of interest in this work.

\section{References}

1. Vardiman JW, Thiele J, Arber DA, et al. The 2008 revision of the World Health Organization (WHO) classification of myeloid neoplasms and acute leukemia: rationale and important changes. Blood. 2009;114(5):937-951. doi:10.1182/blood-2009-03-209262

2. Wang ZY, Chen Z. Acute promyelocytic leukemia: from highly fatal to highly curable. Blood. 2008;111(5):2505-2515. doi:10.1182/blood2007-07-102798

3. Norgaard JM, Friis LS, Kristensen JS, et al. Addressing the room for improvement in management of acute promyelocytic leukemia. Eur J Haematol. 2019;102(6):479-485. doi:10.1111/ejh.13229

4. Zhu HH. The history of the chemo-free model in the treatment of acute promyelocytic leukemia. Front Oncol. 2020;10:592996. doi: $10.3389 /$ fonc. 2020.592996

5. Coombs CC, Tavakkoli M, Tallman MS. Acute promyelocytic leukemia: where did we start, where are we now, and the future. Blood Cancer J. 2015;5(4):e304. doi:10.1038/bcj.2015.25

6. Sanz MA, Montesinos P. Advances in the management of coagulopathy in acute promyelocytic leukemia. Thromb Res. 2020;191(Suppl 1):S63-S67. doi:10.1016/S0049-3848(20)30399-6

7. Powell BL, Moser B, Stock W, et al. Arsenic trioxide improves event-free and overall survival for adults with acute promyelocytic leukemia: North American Leukemia Intergroup Study C9710. Blood. 2010;116(19):3751-3757. doi:10.1182/blood-2010-02-269621

8. Sanz MA, Montesinos P, Rayon C, et al. Risk-adapted treatment of acute promyelocytic leukemia based on all-trans retinoic acid and anthracycline with addition of cytarabine in consolidation therapy for high-risk patients: further improvements in treatment outcome. Blood. 2010;115(25):5137-5146. doi:10.1182/blood-2010-01-266007

9. Avvisati G, Lo-Coco F, Paoloni FP, et al. AIDA 0493 protocol for newly diagnosed acute promyelocytic leukemia: very long-term results and role of maintenance. Blood. 2011;117(18):4716-4725. doi:10.1182/blood-2010-08-302950

10. Ades L, Guerci A, Raffoux E, et al. Very long-term outcome of acute promyelocytic leukemia after treatment with all-trans retinoic acid and chemotherapy: the European APL group experience. Blood. 2010;115(9):1690-1696. doi:10.1182/blood-2009-07-233387

11. Mantha S, Tallman MS, Devlin SM, et al. Predictive factors of fatal bleeding in acute promyelocytic leukemia. Thromb Res. 2018;164 (Suppl 1):S98-S102. doi:10.1016/j.thromres.2018.01.038

12. Tallman MS, Andersen JW, Schiffer CA, et al. All-trans retinoic acid in acute promyelocytic leukemia: long-term outcome and prognostic factor analysis from the North American Intergroup protocol. Blood. 2002;100(13):4298-4302. doi:10.1182/blood-2002-02-0632 
13. Yanada M, Matsushita T, Asou N, et al. Severe hemorrhagic complications during remission induction therapy for acute promyelocytic leukemia: incidence, risk factors, and influence on outcome. Eur J Haematol. 2007;78(3):213-219. doi:10.1111/j.1600-0609.2006.00803.x

14. Zhang Y, Hou W, Wang P, et al. Development of a risk grading system to identify patients with acute promyelocytic leukemia at high risk of early death. Cancer Manag Res. 2018;10:3619-3627. doi:10.2147/CMAR.S167686

15. Naymagon L, Mascarenhas J. Hemorrhage in acute promyelocytic leukemia: can it be predicted and prevented? Leuk Res. 2020;94:106356. doi:10.1016/j.leukres.2020.106356

16. Hou J, Wang S, Zhang Y, et al. Causes and prognostic factors for early death in patients with acute promyelocytic leukemia treated with single-agent arsenic trioxide. Ann Hematol. 2017;96 (12):2005-2013. doi:10.1007/s00277-017-3130-7

17. Zhao H, Zhao Y, Zhang Y, et al. Difference in causes and prognostic factors of early death between cohorts with de novo and relapsed acute promyelocytic leukemia. Ann Hematol. 2018;97(3):409-416. doi:10.1007/s00277-017-3216-2

18. Mantha S, Goldman DA, Devlin SM, et al. Determinants of fatal bleeding during induction therapy for acute promyelocytic leukemia in the ATRA era. Blood. 2017;129(13):1763-1767. doi:10.1182/ blood-2016-10-747170

19. de la Serna J, Montesinos P, Vellenga E, et al. Causes and prognostic factors of remission induction failure in patients with acute promyelocytic leukemia treated with all-trans retinoic acid and idarubicin. Blood. 2008;111(7):3395-3402. doi:10.1182/blood-2007-07-100669

20. McClellan JS, Kohrt HE, Coutre S, et al. Treatment advances have not improved the early death rate in acute promyelocytic leukemia. Haematologica. 2012;97(1):133-136. doi:10.3324/haematol.20 11.046490

21. Park JH, Qiao B, Panageas KS, et al. Early death rate in acute promyelocytic leukemia remains high despite all-trans retinoic acid. Blood. 2011;118(5):1248-1254. doi:10.1182/blood-2011-04-346437

22. Bai Y, Shi M, Yang X, et al. The value of FDP/FIB and D-dimer/FIB ratios in predicting high-risk APL-related thrombosis. Leuk Res. 2019;79:34-37. doi:10.1016/j.leukres.2019.02.007

23. Sanz MA, Lo CF, Martin G, et al. Definition of relapse risk and role of nonanthracycline drugs for consolidation in patients with acute promyelocytic leukemia: a joint study of the PETHEMA and GIMEMA cooperative groups. Blood. 2000;96(4):1247-1253.

24. Sanz MA, Fenaux P, Tallman MS, et al. Management of acute promyelocytic leukemia: updated recommendations from an expert panel of the European LeukemiaNet. Blood. 2019;133 (15):1630-1643. doi:10.1182/blood-2019-01-894980

25. Testi AM, Pession A, Diverio D, et al. Risk-adapted treatment of acute promyelocytic leukemia: results from the International Consortium for Childhood APL. Blood. 2018;132(4):405-412. doi:10.1182/blood-2018-03-836528

26. Minamiguchi H, Fujita H, Atsuta Y, et al. Predictors of early death, serious hemorrhage, and differentiation syndrome in Japanese patients with acute promyelocytic leukemia. Ann Hematol. 2020;99 (12):2787-2800. doi:10.1007/s00277-020-04245-6

27. Hou W, Zhang Y, Jin B, et al. Factors affecting thrombohemorrhagic early death in patients with acute promyelocytic leukemia treated with arsenic trioxide alone. Blood Cells Mol Dis. 2019;79:102351. doi:10.1016/j.bcmd.2019.102351

28. Abla O, Ribeiro RC, Testi AM, et al. Predictors of thrombohemorrhagic early death in children and adolescents with t(15;17)-positive acute promyelocytic leukemia treated with ATRA and chemotherapy. Ann Hematol. 2017;96(9):1449-1456. doi:10.1007/s00277-017-3042-6

29. Song YH, Peng P, Qiao C, et al. Low platelet count is potentially the most important contributor to severe bleeding in patients newly diagnosed with acute promyelocytic leukemia. Onco Targets Ther. 2017;10:4917-4924. doi:10.2147/OTT.S144438
30. Mitrovic M, Suvajdzic N, Bogdanovic A, et al. International society of thrombosis and hemostasis scoring system for disseminated intravascular coagulation $>/=6$ : a new predictor of hemorrhagic early death in acute promyelocytic leukemia. Med Oncol. 2013;30(1):478.

31. Chang H, Kuo MC, Shih LY, et al. Clinical bleeding events and laboratory coagulation profiles in acute promyelocytic leukemia. Eur J Haematol. 2012;88(4):321-328. doi:10.1111/j.16000609.2011.01747.x

32. Dally N, Hoffman R, Haddad N, et al. Predictive factors of bleeding and thrombosis during induction therapy in acute promyelocytic leukemia-a single center experience in 34 patients. Thromb Res. 2005;116(2):109-114. doi:10.1016/j.thromres.2004.11.001

33. Naymagon L, Moshier E, Tremblay D, et al. Predictors of early hemorrhage in acute promyelocytic leukemia. Leuk Lymphoma. 2019;60(10):2394-2403. doi:10.1080/10428194.2019.1581187

34. Rodeghiero F, Avvisati G, Castaman G, et al. Early deaths and anti-hemorrhagic treatments in acute promyelocytic leukemia. A GIMEMA retrospective study in 268 consecutive patients. Blood. 1990;75(11):2112-2117. doi:10.1182/blood.V75.11.2112.2112

35. Breccia M, Latagliata R, Cannella L, et al. Early hemorrhagic death before starting therapy in acute promyelocytic leukemia: association with high WBC count, late diagnosis and delayed treatment initiation. Haematologica. 2010;95(5):853-854. doi:10.3324/haematol.20 09.017962

36. Kim DY, Lee JH, Lee JH, et al. Significance of fibrinogen, D-dimer, and $\mathrm{LDH}$ levels in predicting the risk of bleeding in patients with acute promyelocytic leukemia. Leuk Res. 2011;35(2):152-158. doi:10.1016/j.leukres.2010.05.022

37. Chu T, Wang $\mathrm{H}$, Lv X, et al. Investigation of fibrinogen in early bleeding of patients with newly diagnosed acute promyelocytic leukemia. Platelets. 2020; 1-7. doi:10.1080/09537104.2020.1799969

38. Ikezoe T. Pathogenesis of disseminated intravascular coagulation in patients with acute promyelocytic leukemia, and its treatment using recombinant human soluble thrombomodulin. Int $J$ Hematol. 2014;100(1):27-37. doi:10.1007/s12185-013-1463-0

39. Liu Y, Wang Z, Jiang M, et al. The expression of annexin II and its role in the fibrinolytic activity in acute promyelocytic leukemia. Leuk Res. 2011;35(7):879-884. doi:10.1016/j.leukres.2010.11.008

40. Yan J, Wang K, Dong L, et al. PML/RARalpha fusion protein transactivates the tissue factor promoter through a GAGC-containing element without direct DNA association. Proc Natl Acad Sci U S A. 2010;107(8):3716-3721. doi:10.1073/ pnas.0915006107

41. Zhu J, Guo WM, Yao YY, et al. Tissue factors on acute promyelocytic leukemia and endothelial cells are differently regulated by retinoic acid, arsenic trioxide and chemotherapeutic agents. Leukemia. 1999;13(7):1062-1070. doi:10.1038/sj.leu.2401448

42. Menell JS, Cesarman GM, Jacovina AT, et al. Annexin II and bleeding in acute promyelocytic leukemia. N Engl J Med. 1999;340 (13):994-1004. doi:10.1056/NEJM199904013401303

43. Kaufman RM, Djulbegovic B, Gernsheimer T, et al. Platelet transfusion: a clinical practice guideline from the AABB. Ann Intern Med. 2015;162(3):205-213. doi:10.7326/M14-1589

44. Fogarty PF, Tarantino MD, Brainsky A, et al. Selective validation of the WHO bleeding scale in patients with chronic immune thrombocytopenia. Curr Med Res Opin. 2012;28(1):79-87. doi:10.1185/03007995.2011.644849

45. Miller AB, Hoogstraten B, Staquet M, et al. Reporting results of cancer treatment. Cancer. 1981;47(1):207-214. doi:10.1002/10970142(19810101)47:1<207::AID-CNCR2820470134>3.0.CO;2-6

46. Choudhry A, DeLoughery TG. Bleeding and thrombosis in acute promyelocytic leukemia. Am J Hematol. 2012;87(6):596-603. doi:10.1002/ajh.23158 


\section{Publish your work in this journal}

Cancer Management and Research is an international, peer-reviewed open access journal focusing on cancer research and the optimal use of preventative and integrated treatment interventions to achieve improved outcomes, enhanced survival and quality of life for the cancer patient.
The manuscript management system is completely online and includes a very quick and fair peer-review system, which is all easy to use. Visit http://www.dovepress.com/testimonials.php to read real quotes from published authors.

Submit your manuscript here: https://www.dovepress.com/cancer-management-and-research-journal 